\title{
Practice of ST-segment elevation myocardial infarction care in the Netherlands during four snapshot weeks with the National Cardiovascular Database Registry for Acute Coronary Syndrome
}

\author{
N. P. G. Hoedemaker ${ }^{1}$ M. E. ten Haaf ${ }^{2}$ J. C. Maas ${ }^{3}$ P. Damman ${ }^{1}$-Y. Appelman ${ }^{2}$ J. G. P. Tijssen ${ }^{1}$ R. J. de \\ Winter' $^{1}$ A. W. J. van 't Hof ${ }^{3,4}$
}

Published online: 31 January 2017

(c) The Author(s) 2017. This article is available at SpringerLink with Open Access.

\begin{abstract}
Background Clinical registries provide information on the process of care and patient outcomes, with the potential to improve the quality of patient care. A large Dutch national acute coronary syndrome (ACS) registry is currently lacking. Recently, we initiated the National Cardiovascular Database Registry (NCDR) for ACS in the Netherlands. The purpose of this study was to assess the NCDR ACS registry on feasibility and data completeness during a pilot phase of four snapshot weeks.

Methods Between 2013 and 2015, we invited all hospitals in the Netherlands to record a predefined dataset for every patient that was admitted to their hospital with ST-segment elevation myocardial infarction (STEMI). Data were entered in an online case report form. All patient-specific data were encrypted to ensure privacy.

Results A total of 392 patients were registered in 35 centres. The mean age of the patients was 64 years (SD 13); $8 \%$ of patients presented with signs of cardiogenic shock and $11 \%$ with an out-of-hospital cardiac arrest. The median time from first medical contact to percutaneous coronary intervention (PCI) was $75 \mathrm{~min}$ (IQR 51-108) and this was
\end{abstract}

This Article was provided on behalf of the NVVC ACS working group

$\triangle$ A. W. J. van 't Hof

a.w.j.vant.hof@isala.nl

1 Department of Cardiology, Academic Medical Centre, University of Amsterdam, Amsterdam, The Netherlands

2 Department of Cardiology, VU Medical Centre, VU University Amsterdam, Amsterdam, The Netherlands

3 National Cardiovascular Data Registry, Utrecht, The Netherlands

4 Isala Klinieken Hospital, Zwolle, The Netherlands significantly longer for patients who presented at a non-PCI centre or to a primary care physician. In-hospital and 30day mortality rates were $5.2 \%$ and $7.8 \%$, respectively. The amount of completeness varied, with improved completeness over time.

Conclusion This report shows that a Dutch ACS registry is feasible with respect to STEMI patients. Data completeness, however, was suboptimal. Improved data completeness is warranted for the future.

Keywords ST-elevation myocardial infarction · Registry · Acute coronary syndrome

\section{Introduction}

Within the spectrum of coronary artery disease, acute coronary syndrome (ACS) is a major cause of death, hospitalisation, and high rates of acute complications. In the past decades, there have been improvements in the management of ACS patients. This resulted in a decrease in mortality and morbidity of ACS patients, as shown by registry data $[1,2]$. In addition to monitoring outcomes and quality of care, registries provide the opportunity for hospitals to evaluate the implementation of clinical guidelines. Furthermore, benchmarking of hospital performance has the potential to ultimately improve the quality of care for ACS patients. Finally, national registries provide information on ACS patients who are underrepresented in randomised controlled trials (RCT), for example the elderly and shock patients.

Successful national registration of ACS patients is performed in Sweden, the United States and the United Kingdom and more recently in France, Germany, Poland, and Switzerland [3-9]. In the Netherlands, the National Cardiovascular Data Registry (NCDR) aims to collect national 
data on cardiovascular interventions and device implantations (http://www.ncdr.nl). In addition to the existing registries, the NCDR ACS registry was recently initiated. Hospitals that provide relevant services participate in the collection of data on ST-segment elevation myocardial infarction (STEMI) patients. We report the results of the first four snapshot test weeks of this registry, aiming to assess the feasibility and data completeness of a Dutch ACS registry.

\section{Methods}

\section{Source data and study population}

We used data that derived from the NCDR ACS registry. This registry has enrolled consecutive ACS patients admitted to hospitals in the Netherlands since September 2013. Information is collected prospectively, and the variables in the registry comply with the International Cardiology Audit and Registration Data Standards (CARDS). A description in Dutch is available at http://www.ncdr.nl/registraties/acs. The current analysis consists of all patients presenting with a registered admission diagnosis of STEMI during the four snapshot test weeks held in September 2013, March and September 2014, and May 2015. Hospitals that participated in the data collection are listed in the Appendix. The NCDR ACS working group approved the registry and the current analysis. According to Dutch law, no written informed consent was required.

\section{Organisation and funding}

NCDR is an independent organisation that was founded by the Netherlands Society of Cardiology. The NCDR provides multiple clinical registries, including the ACS registry. This registry is managed by a steering group which includes members of the ACS working committee of the Netherlands Society of Cardiology. The steering group takes care of project management, monitoring, quality and statistical reports. The NCDR ACS registry is self-funded by the participating hospitals and independent from commercial funding. The participating hospitals retain ownership of the patient data they provide.

\section{Data management}

Data are stored on an externally located server and managed by NCDR and Reports BV (Almere, the Netherlands). NCDR is NEN 7510:2011 (a Dutch institute supporting standardisation for data protection) certified for information security in Dutch healthcare. A trusted third party (Zorg TTP, Houten, the Netherlands) encrypts all confidential patient information before it is stored. Independent researchers do not have access to the decryption key. The NCDR ACS dataset includes patient demographics and risk factors, time to treatment, details of reperfusion treatment, and outcomes up to 30 days. The NCDR ACS registry has automatic error-checking routines, including range and consistency checks. For this paper, data were exported from the database on 24 August 2015.

\section{Definitions}

First medical contact (FMC) was defined as the first patient contact with a medical care giver. FMC was subdivided into 1) ambulance (emergency service call), 2) emergency room at a centre performing percutaneous coronary interventions (PCI), 3) emergency room at a non-PCI centre and 4) primary care physician. FMC time was defined as the time of the first diagnostic ECG. PCI time was defined as the time of arrival at the PCI centre. Total ischaemic time was defined as the time from symptom onset until arrival at the PCI centre. Cardiogenic shock was defined as signs of shock (systolic blood pressure $<90 \mathrm{~mm} \mathrm{Hg}$, tachycardia, decreased peripheral circulation, cold extremities, and Killip class 3 or 4 ) during admission at the PCI centre. Outof-hospital-cardiac arrest (OHCA) was defined as cardiac resuscitation initiated before admission to the hospital.

\section{Statistical analysis}

Continuous variables are presented as the mean with standard deviation or median with interquartile range depending on their distribution. Categorical variables are presented as the number with percentage. Comparison of time between different first FMC categories and time of PCI was performed with the Kruskal-Wallis test and Dunn's multiple comparison test. $P$-values $<0.05$ were considered significant.

\section{Results}

\section{Baseline characteristics, time delay, and treatment strategies}

The baseline characteristics and treatment strategies are presented in Table 1. In September 2013, March and September 2014, and May 2015, a total of 329 patients with a STEMI were included in 35 centres. The mean age was 64 years (SD 13) and approximately one-third of the patients were women. At the time of admission, half of the patients were smokers. Of the patients, $8 \%$ presented with signs of cardiogenic shock and $11 \%$ with an OHCA.

The median FMC-to-PCI time was 75 min (IQR 51-108). A total of $66.2 \%$ of the patients first presented in an ambu- 
Table 1 Baseline characteristics of the patients and treatments

\begin{tabular}{|c|c|c|c|c|c|c|c|c|c|}
\hline & Week 1 & & Week 2 & & Week 3 & & Week 4 & & Combined \\
\hline STEMI patients & $N=120$ & $\mathrm{Na} / N$ & $N=123$ & $\mathrm{Na} / N$ & $N=78$ & $\mathrm{Na} / N$ & $N=71$ & $\mathrm{Na} / N$ & $n=392$ \\
\hline \multicolumn{10}{|c|}{ Patient characteristics } \\
\hline Mean age (SD) & $65(12)$ & $0 / 120$ & $64(14)$ & $0 / 123$ & $61(13)$ & $0 / 78$ & $64(13)$ & $0 / 71$ & $64(13)$ \\
\hline Women & $34.2 \%$ & $0 / 120$ & $32.5 \%$ & $0 / 123$ & $29.5 \%$ & $0 / 78$ & $21.1 \%$ & $0 / 71$ & $30.4 \%$ \\
\hline Current smokers & $60.3 \%$ & $57 / 120$ & $36.5 \%$ & $38 / 123$ & $48.3 \%$ & $20 / 78$ & $53.7 \%$ & $17 / 71$ & $48.5 \%$ \\
\hline Cardiogenic shock & $9.6 \%$ & $16 / 120$ & $8.8 \%$ & $32 / 123$ & $9.2 \%$ & $13 / 78$ & $4.5 \%$ & $4 / 71$ & $8.3 \%$ \\
\hline OHCA & $5.7 \%$ & $15 / 120$ & $12.2 \%$ & $33 / 123$ & $16.9 \%$ & $13 / 78$ & $10.1 \%$ & $2 / 71$ & $10.6 \%$ \\
\hline \multicolumn{10}{|l|}{ First medical contact } \\
\hline Ambulance & $64.1 \%$ & $17 / 120$ & $65.5 \%$ & $7 / 123$ & $63.8 \%$ & $9 / 78$ & $62.8 \%$ & $1 / 71$ & $64.2 \%$ \\
\hline ER PCI centre & $13.6 \%$ & $17 / 120$ & $6.0 \%$ & $7 / 123$ & $5.8 \%$ & $9 / 78$ & $4.3 \%$ & $1 / 71$ & $7.8 \%$ \\
\hline ER non-PCI centre & $9.7 \%$ & $17 / 120$ & $21.6 \%$ & $7 / 123$ & $15.9 \%$ & $9 / 78$ & $18.6 \%$ & $1 / 71$ & $16.5 \%$ \\
\hline $\begin{array}{l}\text { Primary care } \\
\text { physician }\end{array}$ & $12.6 \%$ & $17 / 120$ & $6.9 \%$ & $7 / 123$ & $14.5 \%$ & $9 / 78$ & $14.3 \%$ & $1 / 71$ & $11.5 \%$ \\
\hline \multicolumn{10}{|l|}{ Intervention } \\
\hline CAG & $100 \%$ & $0 / 120$ & $100 \%$ & $0 / 123$ & $100 \%$ & $8 / 78$ & $86.8 \%$ & $3 / 71$ & $95.6 \%$ \\
\hline Radial access & $45.9 \%$ & $11 / 120$ & $54.2 \%$ & $16 / 123$ & $71.6 \%$ & $3 / 70$ & $86.2 \%$ & $1 / 59$ & $60.4 \%$ \\
\hline PCI after CAG & $95.6 \%$ & $75 / 120$ & $94.4 \%$ & $15 / 123$ & $94.0 \%$ & $3 / 70$ & $96.6 \%$ & $0 / 59$ & $95.0 \%$ \\
\hline $\begin{array}{l}\text { Thrombus aspira- } \\
\text { tion }\end{array}$ & $69.2 \%$ & $30 / 43$ & $55.0 \%$ & $82 / 102$ & $34.6 \%$ & $11 / 63$ & $28.90 \%$ & $19 / 57$ & $39.8 \%$ \\
\hline Successful PCI & $100 \%$ & $25 / 43$ & $100 \%$ & $57 / 102$ & $98.3 \%$ & $5 / 63$ & $97.5 \%$ & $17 / 57$ & $98.8 \%$ \\
\hline \multicolumn{10}{|l|}{ Time delay } \\
\hline FMC-to-PCI time & $75(48-152)$ & $16 / 43$ & $80(52-109)$ & $20 / 102$ & $74(57-112)$ & $13 / 63$ & $61(51-92)$ & $14 / 57$ & $75(51-108)$ \\
\hline $\begin{array}{l}\text { Total ischaemic } \\
\text { time }\end{array}$ & $\begin{array}{l}163 \\
(75-440)\end{array}$ & $18 / 43$ & $\begin{array}{l}165 \\
(126-246)\end{array}$ & $23 / 102$ & $\begin{array}{l}167 \\
(102-328)\end{array}$ & $15 / 63$ & $\begin{array}{l}168 \\
(107-293)\end{array}$ & $14 / 57$ & $\begin{array}{l}165 \\
(106-287)\end{array}$ \\
\hline
\end{tabular}

$\mathrm{Na}$ number of missing values filled in on the case report form, $N$ number of completed case report forms available, STEMI ST-segment elevation myocardial infarction, $S D$ standard deviation, $O H C A$ out-of-hospital cardiac arrest, $E R$ emergency room, $P C I$ percutaneous coronary intervention, $I Q R$ interquartile range, $F M C$ first medical contact, $C A G$ coronary angiography

Time is in minutes

Table 2 Time of first medical contact to percutaneous coronary intervention

\begin{tabular}{|c|c|c|c|c|}
\hline First medical contact & $N$ & Percentage & Time to PCI (min) & $p$-value* \\
\hline Ambulance & 133 & 66.2 & $69(50-92)$ & - \\
\hline ER PCI centre & 14 & 7.0 & $78.5(46.5-126.3)$ & NS \\
\hline ER non-PCI centre & 34 & 16.9 & $97.5(64.5-129)$ & $p<0.05$ \\
\hline Primary care physician & 20 & 9.9 & $96(65.8-174.3)$ & $p<0.01$ \\
\hline
\end{tabular}

$E R$ emergency room, $P C I$ percutaneous coronary intervention, $N S$ not significant, * compared with ambulance

Time displayed as mean with interquartile range

lance and these patients had the lowest FMC-to-PCI time (69 min, IQR 50-92). Patients presenting in an ambulance also had a significantly lower FMC-to-PCI time compared with those who presented at a non-PCI centre or a primary care physician, as is displayed in Table 2.

Catheterisation was performed via the radial artery in $60.4 \%$ of the patients and thrombus aspiration was used in $39.8 \%$. There was an increase in the use of radial access and a decrease in the use thrombus aspiration in 2015, compared with 2013. Primary PCI was performed in $95.0 \%$ of patients, of which $98.8 \%$ was successful.

\section{Outcomes}

The rate of in-hospital complications was $13.5 \%$, as is displayed in Table 3. The rates of in-hospital and 30-day mortality were $5.2 \%$ and $7.8 \%$ respectively. The use of dual antiplatelet therapy, beta-blockers and statins was slightly under $90 \%$ and anticoagulants were prescribed in $18.5 \%$. Of the patients, $87.7 \%$ were offered a place in a cardiac rehabilitation program of whom $80.9 \%$ are known to have participated. 
Table 3 Outcomes, medication at discharge and cardiac rehabilitation

\begin{tabular}{|c|c|c|c|c|c|c|c|c|c|}
\hline & Week 1 & & Week 2 & & Week 3 & & Week 4 & & Combined \\
\hline STEMI patients & $N=120$ & $\mathrm{Na} / N$ & $N=123$ & $\mathrm{Na} / N$ & $N=78$ & $\mathrm{Na} / N$ & $N=71$ & $\mathrm{Na} / N$ & $N=392$ \\
\hline \multicolumn{10}{|l|}{ Outcomes } \\
\hline In-hospital complications & $14.5 \%$ & $51 / 120$ & $7.3 \%$ & $41 / 123$ & $28.6 \%$ & $50 / 78$ & $14.0 \%$ & $21 / 71$ & $13.5 \%$ \\
\hline In-hospital mortality & $2.9 \%$ & $51 / 120$ & $2.4 \%$ & $41 / 123$ & $14.30 \%$ & $50 / 78$ & $8.0 \%$ & $21 / 71$ & $5.2 \%$ \\
\hline 30-day mortality & $3.5 \%$ & $35 / 120$ & $7.1 \%$ & $67 / 123$ & $13.2 \%$ & $40 / 78$ & $13.2 \%$ & $33 / 71$ & $7.8 \%$ \\
\hline \multicolumn{10}{|l|}{ Medication at discharge } \\
\hline Acetylsalicylic acid & $82.5 \%$ & $23 / 120$ & $90.6 \%$ & $38 / 123$ & $95.8 \%$ & $30 / 78$ & $93.3 \%$ & $41 / 71$ & $88.8 \%$ \\
\hline P2Y12 inhibitors & $82.8 \%$ & $21 / 120$ & $91.7 \%$ & $27 / 123$ & $93.90 \%$ & $29 / 78$ & $80.0 \%$ & $41 / 71$ & $87.6 \%$ \\
\hline Beta-blocker & $67.4 \%$ & $25 / 120$ & $81.3 \%$ & $43 / 123$ & $93.0 \%$ & $35 / 78$ & $93.3 \%$ & $41 / 71$ & $87.6 \%$ \\
\hline Statin & $80.4 \%$ & $28 / 120$ & $91.4 \%$ & $42 / 123$ & $95.3 \%$ & $35 / 78$ & $93.3 \%$ & $41 / 71$ & $88.2 \%$ \\
\hline Anticoagulants & $15.7 \%$ & $31 / 120$ & $25.4 \%$ & $52 / 123$ & $50.0 \%$ & $39 / 78$ & $3.6 \%$ & $43 / 71$ & $18.5 \%$ \\
\hline \multicolumn{10}{|l|}{ Cardiac rehabilitation } \\
\hline Cardiac rehabilitation proposed & $91.8 \%$ & $59 / 120$ & $88.2 \%$ & $72 / 123$ & $78.8 \%$ & $45 / 78$ & $88.0 \%$ & $46 / 71$ & $87.7 \%$ \\
\hline Cardiac rehabilitation attended & $70.0 \%$ & $16 / 56$ & $91.7 \%$ & $21 / 45$ & $88.2 \%$ & $9 / 26$ & $77.8 \%$ & $13 / 22$ & $80.9 \%$ \\
\hline
\end{tabular}

$\mathrm{Na}$ number of missing values filled in on the case report form, $N$ number of completed case report forms available

STEMI ST-segment elevation myocardial infarction

\section{Missing data}

Information on missing data can be found in Table 1 and 3 . The data completeness of patient characteristics and information on FMC and intervention improved over the course of the four weeks. Data completeness for these categories generally increased by $50 \%$ or more. The percentage of missing data on time delay indicators decreased slightly.

The amount of missing data on in-hospital outcome was lower in 2015 compared with 2013, whereas missing data on 30-day mortality increased. In addition, an increase in missing data was also found for information on discharge medication and cardiac rehabilitation.

\section{Discussion}

The current report describes the first results of the Dutch NCDR ACS registry with respect to STEMI patients. The first data were collected during four snapshot test weeks between 2013 and 2015 and show that a national registry for STEMI patients is feasible. However, with suboptimal data completeness, improvement is of upmost importance.

\section{Outcomes of an unselected population}

This registry showed in-hospital and 30-day mortality rates of $5.2 \%$ and $7.8 \%$, respectively. To put this into context, 30-day mortality rates of STEMI patients enrolled in various major RCTs conducted from 2009 to 2013 ranged from $2.0-3.3 \%$ [10-13]. For this registry no patients were excluded and we aimed to collect data that reflect real-world practice. Almost $10 \%$ of patients presented after an OHCA and $8 \%$ presented in cardiogenic shock. In addition, 5\% of patients did not receive reperfusion therapy, mainly because of late presentation or frailty. This may explain the higher mortality rate. A higher in-hospital mortality rate was also found in Denmark (10.9\%, 95\% CI 7.0-14.7) and in a snapshot of Western European countries $(6.3 \%)$ [14, 15]. In addition, the Swedish and the British registries show 30-day mortality rates of $8.6 \%$ (95\% CI 8.3-8.8) and $11.2 \%$ (95\% CI 11.1-11.4) respectively [1]. The results from our registry showed lower mortality rates; however, these derived from a small sample size and thus, comparison with results from other registries should be done with care.

\section{Trends in practice}

Registries can help to identify trends in practice of care over the years. Our results show an increase in the use of radial access and a decrease in the use of thrombus aspiration in 2015, compared with the first snapshot test week in 2013. These results may reflect the impact of the latest trials that were conducted in these areas and follow recommendations of guidelines [16-20].

\section{National registries}

Clinical registries are necessary in order to monitor outcomes and ultimately help improve the quality of care. Examples of successful national registries include the Myocardial Ischaemia National Audit Project (MINAP) from the United Kingdom, the American NCDR CathPCI registry, and the Swedish Web-system for Enhancement and Development of Evidence-based care in Heart disease Evaluated According to Recommended Therapies (SWEDE- 
HEART) [7-9]. The SWEDEHEART registry has demonstrated the positive impact of evidence-based treatments on outcomes. In a report that included STEMI patients between 1996-2007, an increase in the use of evidence-based treatments was associated with a sustained decrease in 30day and 1-year mortality during the same period of time [21]. In addition, registries have expanded their roles and are also used for multi-centre observational research and more recently, registry-based RCTs [22]. Furthermore, international collaborations can be initiated, potentially giving insight into differences in patient characteristics and treatments among countries [23, 24].

At a national level, the NCDR ACS registry can be used as an instrument for quality improvements in hospitals. A retrospective study showed that Dutch hospitals use dissimilar definitions to determine performance indicators for STEMI patients [25]. The use of predefined key performance and quality indicators, which correspond with those required by the Dutch Health Inspectorate and the Dutch Safety Management System, can solve this problem and offers a universal method to compare hospitals at a national level. This can potentially create opportunities to reduce complications, and reveal targets for improvement.

\section{Future perspectives}

This report shows the first test on feasibility and data completeness of a national Dutch ACS registry. A total of 35 centres have participated at least once, and have thereby been introduced to be part of the NCDR ACS registry and the process of providing data to NCDR. In order to catch up with registries from surrounding countries, we need to further develop the Dutch registration.

Firstly, our main goal is to involve all Dutch hospitals in the registry and start continuous inclusion of all ACS patients. However, a common problem for hospitals is the workload of the registration, which is needed to guarantee the quality and completeness of the data. Currently, not every Dutch hospital has a registration nurse, which may cause hospitals to provide an incomplete dataset or to withdraw from the national registry. Therefore, we encourage all Dutch hospitals to recruit a dedicated registration nurse. Possibly, this could be supported by Dutch government institutions or health insurance companies, since a successful registry can contribute to improving the quality of care. In addition, we want to develop ways to link the national registry to insurance, pharmacy, and hospital databases, in order to collect follow-up data beyond 30 days after admission.

Secondly, we aim to expand the ACS registry to include patients with non-ST-elevation-ACS (NSTE-ACS). Registration of NSTE-ACS can be challenging because of the heterogeneity of the population; however, it will provide further insight into the use of antiplatelet and antithrombotic therapy or differences between PCI and non-PCI centres regarding timing of intervention in NSTE-ACS [26-28].

For the future, we want to integrate and link different electronic patient records (EPRs) in order to allow direct data capture from the patient records, which will minimise the extra work associated with data entry. The first experiences with direct registration from existing EPRs are encouraging. As mentioned previously, the NCDR ACS registry will serve as a platform for national quality improvement efforts. Beyond this primary goal, international collaborations and research will be important other goals.

\section{Limitations}

Several limitations must be taken into account. Our results are based on registry data and may be subject to some selection bias. We invited all hospitals in the Netherlands to report consecutive STEMI cases; however, participation in the registry was voluntary. Overall, 18 of 55 non-PCI (32\%) and 17 of the $30 \mathrm{PCI}(57 \%)$ centres participated and therefore our results may not fully reflect the whole STEMI population in the Netherlands. Despite this limited participation and patient numbers, our results seem to provide an adequate representation of an unselected Dutch STEMI population.

\section{Conclusion}

The NCDR ACS registry is a national program that aims to enrol consecutive ACS patients presenting to hospitals in the Netherlands. The results from four snapshot test weeks show that a Dutch national ACS registry is feasible. Data completeness, however, was suboptimal. Improved data completeness, is warranted for the future.

Acknowledgements We thank all the participating hospitals and patients contributing to the NCDR ACS registry. Special acknowledgement to Esther Zwaan and Ineke Stam.

Conflict of interest N.P.G. Hoedemaker, M.E. ten Haaf, J.C. Maas, P. Damman, Y. Appelman, J.G.P. Tijssen, R.J. de Winter and A.W.J. van 't Hof declare, that they have no competing interests.

Open Access This article is distributed under the terms of the Creative Commons Attribution 4.0 International License (http:// creativecommons.org/licenses/by/4.0/), which permits unrestricted use, distribution, and reproduction in any medium, provided you give appropriate credit to the original author(s) and the source, provide a link to the Creative Commons license, and indicate if changes were made. 


\section{Appendix}

\section{NVVC ACS working group}

A.W.J. van 't Hof (chair), Y. Appelman, J.M. ten Berg, A.H. Liem, W.R.P. Agema, T.J.F. ten Cate, P. Damman, I.J van Eede, D.J. van der Heijden, J.W. Jukema, G.J. Laarman, R.J.G. Peters, M.L.J. Schaik-van der Wielen, P.W.J.C. Serruys, W.A.L. Tonino, R.A. Waalewijn, F.F. Willems, R.J. de Winter

\section{NCDR ACS steering committee}

A.W.J. van 't Hof (chair), J.M. ten Berg, P. Damman, J.G.P.Tijssen, V.A.W.M. Umans, T.W. Galema

\section{NCDR PCI steering committee}

W.R.M. Aengevaeren, Y. Appelman, A.W.J. van 't Hof, M. Meuwissen, A.A.C.M. Heestermans, J.G.P. Tijssen, VA.W.M. Umans, T.W. Galema

\section{List of participating centres}

Academic Medical Center - University of Amsterdam, Albert Schweitzer Hospital, Alrijne Hospital Leiderdorp, Amphia Hospital, Antonius Hospital, Bethesda Hospital, BovenIJ Hospital, Bronovo Hospital, Catharina Hospital, Deventer Hospital, Sint Franciscus Gasthuis Hospital, Gelre Hospital Apeldoorn, Gemini Hospital, Groene Hart Hospital, Haga Hospital Leyweg, Isala Hospital, Jeroen Bosch Hospital , Leiden University Medical Center, Maasstad Hospital, Medical Center Alkmaar, Rijnstate Hospital, Rode Kruis Hospital, St. Antonius Hospital, TweeSteden Hospital, University Medical Center Groningen, Münster University Hospital, University Medical Center St Radboud, VU Medical Center Westfries Gasthuis Hospital, Hospital Rivierenland, Hospital St Jansdal, Ziekenhuisgroep Twente Hospital (Hengelo), Zorggroep Noorderbreedte Hospital, ZorgSaam Zeeuws-Vlaanderen Hospital, Zuyderland Medical Center Heerlen

\section{References}

1. Fox KA, Steg PG, Eagle KA. et al. Decline in Rates of Death and Heart Failure in Acute Coronary Syndromes, 1999-2006. JAMA. 2007;297(17):1892-900.

2. Yeh RW, Sidney S, Chandra M, et al. Population trends in the incidence and outcomes of acute myocardial infarction. N Engl J Med. 2010;362:2155-65.

3. Zeymer U, Heuer H, Schwimmbeck P, et al. Guideline-adherent therapy in patients with acute coronary syndromes. Epicor Regist Ger Herz. 2015;40(Suppl 1):27-35.

4. Radovanovic D, Erne P. AMIS Plus: Swiss registry of acute coronary syndrome. Heart. 2010;96:917-21.
5. Polonski L, Gasior M, Gierlotka M, et al. Polish Registry of Acute Coronary Syndromes (PL-ACS). Characteristics, treatments and outcomes of patients with acute coronary syndromes in Poland. Kardiol Pol. 2007;65:861-72, discussion 73-4.

6. Hanssen M, Cottin Y, Khalife K, et al. French Registry on Acute ST-elevation and non ST-elevation Myocardial Infarction 2010. FAST-MI 2010. Heart. 2012;98:699-705.

7. Herrett E, Smeeth L, Walker L, Weston C. The Myocardial Ischaemia National Audit Project (MINAP). Heart. 2010;96:1264-7.

8. Moussa I, Hermann A, Messenger JC, et al. The NCDR CathPCI Registry: a US national perspective on care and outcomes for percutaneous coronary intervention. Heart. 2013;99:297-303.

9. Jernberg T, Attebring MF, Hambraeus K, et al. The Swedish Websystem for enhancement and development of evidence-based care in heart disease evaluated according to recommended therapies (SWEDEHEART). Heart. 2010;96:1617-21.

10. Schulz S, Richardt G, Laugwitz KL, et al. Prasugrel plus bivalirudin vs. clopidogrel plus heparin in patients with ST-segment elevation myocardial infarction. Eur Heart J. 2014;35:2285-94.

11. Frobert O, Lagerqvist B, Olivecrona GK, et al. Thrombus aspiration during ST-segment elevation myocardial infarction. N Engl J Med. 2013;369:1587-97.

12. Montalescot G, van 't Hof AW, Lapostolle F, et al. Prehospital ticagrelor in ST-segment elevation myocardial infarction. N Engl J Med. 2014;371:1016-27.

13. Steg PG, van 't Hof A, Hamm CW, et al. Bivalirudin started during emergency transport for primary PCI. N Engl J Med. 2013;369:2207-17.

14. Terkelsen CJ, Lassen JF, Nørgaard BL, et al. Mortality rates in patients with ST-elevation myocardial infarction vs. non-ST-elevation acute myocardial infarction: observations from an unselected cohort. Euro Heart J. 2005;26(1):18-26.

15. Puymirat E, Battler A, Birkhead J, et al. Euro Heart Survey 2009 Snapshot: regional variations in presentation and management of patients with AMI in 47 countries. Eur Heart $\mathbf{J}$ Acute Cardiovasc Care. 2013;2:359-70.

16. Bernat I, Horak D, Stasek J, et al. ST-segment elevation myocardial infarction treated by radial or femoral approach in a multicenter randomized clinical trial: the STEMI-RADIAL trial. J Am Coll Cardiol. 2014;63:964-72.

17. Jolly SS, Cairns JA, Yusuf S, et al. Outcomes after thrombus aspiration for ST elevation myocardial infarction: 1-year follow-up of the prospective randomised TOTAL trial. Lancet. 2016;387:127-35.

18. Karrowni W, Vyas A, Giacomino B, et al. Radial versus femoral access for primary percutaneous interventions in ST-segment elevation myocardial infarction patients: a meta-analysis of randomized controlled trials. JACC Cardiovasc Interv. 2013;6:814-23.

19. Lagerqvist B, Frobert O, Olivecrona GK, et al. Outcomes 1 year after thrombus aspiration for myocardial infarction. $\mathrm{N}$ Engl J Med. 2014;371:1111-20.

20. Mehta SR, Jolly SS, Cairns J, et al. Effects of radial versus femoral artery access in patients with acute coronary syndromes with or without ST-segment elevation. J Am Coll Cardiol. 2012;60:2490-9.

21. Jernberg T, Johanson P, Held C, et al. Association between adoption of evidence-based treatment and survival for patients with STelevation myocardial infarction. JAMA. 2011;305:1677-84.

22. Frobert O, James SK. Thrombus aspiration during myocardial infarction. N Engl J Med. 2014;370:675-6.

23. McNamara RL, Chung SC, Jernberg T, et al. International comparisons of the management of patients with non-ST segment elevation acute myocardial infarction in the United Kingdom, Sweden, and the United States: The MINAP/NICOR, SWEDEHEART/ RIKS-HIA, and ACTION Registry-GWTG/NCDR registries. Int J Cardiol. 2014;175:240-7. 
24. Chung SC, Gedeborg R, Nicholas O, et al. Acute myocardial infarction: a comparison of short-term survival in national outcome registries in Sweden and the UK. Lancet. 2014;383:1305-12.

25. Verweij LM, Tra J, Engel J, et al. Data quality issues impede comparability of hospital treatment delay performance indicators. Neth Heart J. 2015;23:420-7.

26. Verheugt FW. Trials, registries and guidelines for non-ST-elevation acute coronary syndromes. Neth Heart J. 2014;22:52-4.

27. Badings EA, Remkes WS, Dambrink JH, et al. Timing of intervention in high-risk non-ST-elevation acute coronary syndromes in PCI versus non-PCI centres : Sub-group analysis of the ELISA-3 trial. Neth Heart J. 2016;24:181-7.

28. Oosterwerff EF, Fagel ND, Slagboom T, et al. Impact of percutaneous coronary intervention timing on 5-year outcome in patients with non-ST-segment elevation acute coronary syndromes. The 'wait a day' approach might be safer. Neth Heart J. 2016;24:173-80. 